\title{
Controle do pulgão da erva-doce Hyadaphis foeniculi e seletividade em
}

\author{
abelhas Apis mellifera \\ Control of fennel aphid Hyadaphis foeniculi and selectivity in bees Apis mellifera \\ Haron Salvador Reinaldo 1 \\ Graduado em Agronomia, Centro de Ciências Agrárias, UFPB Campus Areia \\ Email: haron.salvador25@gmail.com \\ Robério de Oliveira 2 \\ Doutor em Agronomia, Centro de Ciências Agrárias, UFPB Campus Areia \\ E-mail: roberio_b19@yahoo.com.br \\ Mileny dos Santos de Souza 3 \\ Msc. em Agronomia, Centro de Ciências Agrárias, UFPB Campus Areia. \\ E-mail: mileny.lopes67@gmail.com \\ Izabela Nunes do Nascimento 4 \\ Msc. em Agronomia, Centro de Ciências Agrárias, UFPB Campus Areia \\ E-mail: izabelaufpb@gmail.com \\ José Luiz do Nascimento Júnior 5 \\ Doutor em Agronomia, Centro de Ciências Agrárias, UFPB, Campus Areia \\ E-mail: jlnjunioragro@hotmail.com
}

Jacinto de Luna Batista 6

Prof. Associado IV, Dept ${ }^{o}$ de Fitotecnia e Ciências Ambientais, DFCA, Centro de Ciências Agrárias,

Resumo: A cultura da erva-doce Foeniculum vulgare tem grande importância no Nordeste brasileiro. O principal problema fitossanitário dessa cultura é o pulgão Hyadaphis foeniculi, que tem causado danos consideráveis, levando a aplicação de inseticidas. O uso de desses produtos, além de não recomendados para a cultura provoca redução de insetos benéficos, os agentes de controle natural e as abelhas, que formam um grupo muito diverso e diferente quanto à vulnerabilidade a exposição aos inseticidas. Considerando estes aspectos, esse trabalho teve como objetivo avaliar produtos eficientes no controle do pulgão da erva-doce $H$. foeniculi e a seletividade a abelha Apis mellifera. As abelhas e os pulgões foram coletadas em campo e submetidos a testes usando os seguintes produtos: detergente mais óleo, Prev-am e Provado ${ }^{\circledR} 200$ SC, usando-se cinco repetições cada tratamento. Os dados de mortalidade foram submetidos às fórmulas de correção da mortalidade, Sun-Shepard e Abbott. Os tratamentos Óleo + Detergente, Prevam e Provado ${ }^{\circledR} 200 \mathrm{SC}$, controlaram eficientemente os pulgões chegando a índices de $100 \%$ de mortalidade, no entanto esses produtos não são seletivos para a espécie de abelha A. mellifera.

Palavras-chave: Controle químico; inseto-praga; polinizadores.

Abstract: The fennel Foeniculum vulgare has great importance in the Brazilian Northeast. The principal insect-pest of this culture is the aphid Hyadaphis foeniculi, 
which has caused many considerable damage. The use of insecticides can cause reduction of beneficial insects like honeybees that form a very diverse group and different about the vulnerability exposure of insecticides. So, the work aimed to evaluate efficient products in aphid control of fennel $\mathrm{H}$. foeniculi and their selectivity to bee Apis mellifera. Bees and aphids were collected in the field and were submitted to different products: detergent + oil, Prev-am and Provado ${ }^{\circledR} 200$ SC. We used five replicates for each product, the mortality data were submitted to formula of mortality correction: Sun-Shepard and Abbott. The products used showed efficient control of aphids arriving at rates of $100 \%$ mortality, nevertheless these products caused deaths in bees with about $40 \%$, showing non selectivity.

Keywords: Chemical control; insect-pest; pollinators.

\section{Introdução}

A cultura da erva-doce Foeniculum vulgare L. foi introduzida no Brasil pelos primeiros colonos, é cultura cultivada nas regiões tropicais e temperadas, originária do Mediterrâneo e conhecida desde os Romanos, Gregos e Egípcios (SANTANA, 1994). A cultura tem grande importância no nordeste brasileiro especialmente para pequenos produtores por isso tem sido muito cultivada na região, principalmente nos estados da Paraíba e Pernambuco. A erva-doce é conhecida por suas propriedades terapêuticas (digestivo, diurética e anti-inflamatória) (EL-AWADI e HASSAN, 2011) e culinárias com sopas, tortas e bolos, e também efeito inseticida (ABRAMSON et al., 2006; ABRAMSON et al., 2007a; ABRAMSON et al., 2007b) propriedades fungicidas (SINGH et al., 2006). Tem, portanto, um mercado garantido no nordeste do Brasil e é importante para a agricultura familiar na região (RAMALHO et al., 2012).

O principal problema fitossanitário que ocorre na cultura da erva-doce na Paraíba é o pulgão Hyadaphis foeniculi Passerini, 1860 (Hemiptera: Aphididae), que tem causado muitos danos consideráveis nessa cultura com isso os agricultores tem se desestimulado com esse cultivo (SANTOS et al., 2002). Este afídeo ataca principalmente flores, fruto das plantas e através da sucção continua da seiva ocorre à murcha e a secagem dessas flores e frutos, causando uma redução da produtividade esses afídeo também expele um liquido açucarado favorecendo o crescimento de fumagina. Sendo transmissor de pelo menos 12 tipos de vírus dentre eles o Mosaic potyvirus, Yellow spot luteovirus, e Honeysuckle latent carlavirus (FERREIRA e SOUSA-SILVA, 2004). De acordo com Sousa-Silva e Ilharco (1995), seu hospedeiro primário é Lonicera spp. (Caprifoliaceae), e os secundários, umbelíferas. 
Apesar de não existir nenhum produto químico registrado no Ministério da Agricultura para a referida cultura, relatos dos produtores apontam que o uso de inseticidas sintéticos tem sido utilizado rotineiramente para o controle desse inseto-praga. O uso desses inseticidas veem causando redução de insetos benéficos além da contaminação do solo e ambiente. $\mathrm{O}$ uso indiscriminado de agroquímicos vem trazendo consequências gravíssimas como mortes a animais; mortes por intoxicação em pessoas; e volubilidade de agroecossistemas, com a morte de inimigos naturais das pragas, e resistência dessas pragas aos tóxicos (RAMOS, 2002). Os produtos domissanitários foram apontados como alternativa ao uso de agrotóxicos, pois são biodegradáveis além de serem seletivos (LOPES, 2003; CARVALHO, 2005).

Além dos fatores supracitados, tem aumentado a preocupação dos especialistas com os possíveis efeitos dos agrotóxicos sobre as populações de abelhas. Malaspina e Silva-Zacarin (2006) sugeriram que a redução no número de espécies de abelhas é decorrente do aumento da atividade de forrageamento desses insetos em culturas tratadas com pesticidas, e tem-se observado o declínio de colônias de abelhas Apis mellifera L. em várias regiões do mundo. Nos últimos anos houve um aumento de perdas repentinas de colônias de abelhas nos Estados Unidos da América (EUA) (NEUMANN e CARRECK, 2010). Foi verificado no Reino Unido, entre os anos de 1989 e 2003 uma redução populacional das espécies de abelhas, e esta redução está relacionada com aplicações de inseticidas dos grupos: organofosforados, carbamatos e piretroides (BARNETT et al., 2007).

As abelhas formam um grupo muito diverso e diferentes quanto à vulnerabilidade a exposição de inseticidas sendo que os padrões de referências para inúmeras espécies veem da A. mellifera. Atkins et al. (1981) avaliaram os efeitos de 399 produtos sobre abelhas em nível de laboratório e de campo, e constataram que $20 \%$ foram extremamente tóxicos a A. mellifera, $15 \%$ moderadamente tóxicos e $65 \%$ apresentaram baixa toxicidade ou foram inócuos. Este trabalho teve como objetivo avaliar produtos eficientes no controle do pulgão da erva-doce $H$. foeniculi e sua seletividade a abelha $A$. mellifera.

\section{Metodologia}

O estudo foi conduzido no Laboratório de Entomologia do Departamento de Fitotecnia e Ciências Ambientais do Centro de Ciências Agrárias na Universidade Federal da Paraíba, (CCA/UFPB). A pesquisa foi realizada através da aplicação de produtos 
químicos e alternativos sobre o pulgão $H$. foeniculi e sobre a abelha $A$. mellifera. O pulgão foi coletado em plantas de erva-doce no munícipio de Alagoa Nova, PB, e as abelhas foram provenientes do Setor de Apicultura do CCA/UFPB.

Coleta e aplicação dos produtos sobre os pulgões

Coletaram-se umbelas de plantas de erva-doce infestadas com colônias do pulgão $H$. foeniculi, levadas para o Laboratório de Entomologia onde foram separadas e padronizadas. Após a aplicação dos produtos, as colônias dos pulgões foram colocadas em placas de Petri $(9,0 \mathrm{~cm}$ de diâmetro x 1,5 cm de altura) contendo um chumaço de algodão umedecido para manter a turgescência da umbela, cobertas com plástico filme PVC tipo Wida.

A aplicação dos produtos (químicos e alternativos) foi feita através da imersão das colônias dos pulgões durante três segundos em 100ml da solução. Foram utilizados quatro tratamentos (produtos) e cinco repetições. T1 - Água destilada; T2- Prev-am (Sodium tetraborohydrate decahydrate) $(5 \mathrm{ml} / \mathrm{L})$; T3 - Óleo de Linhaça $(1 \%)+$ Detergente (1\%); T4 - Provado ${ }^{\circledR} 200 \mathrm{SC}(0,82 \mathrm{ml} / \mathrm{L})$.

A avaliação do tratamento foi feita após 24 horas da aplicação através da taxa de mortalidade dos pulgões, observado sob microscópio estereoscópio com aumento de 20x.

Coleta e aplicação dos produtos sobre as abelhas

As abelhas foram capturadas em potes plásticos de $600 \mathrm{ml}$, em cada recipiente foram acondicionadas três abelhas, fechadas com tecido voil. Utilizaram-se os mesmos produtos e concentrações utilizadas no tratamento dos pulgões, no entanto, o modo de aplicação nas abelhas foi feito através da pulverização com micropulverizador (borrifador manual), com volume médio de pulverização de $0,5 \mathrm{ml}$. Antes da aplicação as abelhas foram colocadas a temperaturas de $-10^{\circ} \mathrm{C}$ por um minuto para ficarem em estado de repouso. Colocou-se também água e uma mistura de mel e água a 30\% com o propósito de evitar morte das abelhas por desnutrição. A avaliação da mortalidade das abelhas foi verificada até 24 horas da aplicação dos produtos.

Análise estatística e correção da eficiência de mortalidade 
O delineamento estatístico utilizado foi o inteiramente casualizado (DIC) tendose os dados submetidos à análise de variância ANOVA, e as médias comparadas pelo teste de Tukey (5\%).

Os dados de mortalidade dos produtos foram submetidos a fórmulas de correção da mortalidade, para o H. foeniculi usou-se fórmula de Sun Shepard (PÜNTENER, 1981) que é usada com população desuniforme e mortalidade (\%), já a abelha A. mellifera que tinha população uniforme foi usada a fórmula de Abbott (1925).

Sun Shepard (PÜNTENER, 1981)

$$
\operatorname{Mc}(\%)=\frac{\% \mathrm{Mo}-\% \mathrm{Mt}}{100-\% \mathrm{Mt}}
$$

Mc- Mortalidade corrigida

Mo- Mortos observado no tratamento

Mt- Mortos observados na testemunha

Abbott (1925)

\section{$\mathrm{E} \%=\underline{\text { Mortos no tratamento }(\%) \times \text { Mortos no teste }(\%)}$}

100-_Mortos no teste(\%)

\section{Resultados e Discussão}

Mortalidades do pulgão $H$. foeniculi

Os produtos utilizados apresentaram eficiência no controle ao pulgão, no entanto entre eles foram observadas diferenças significativas (Tabela 1). O uso de óleos vegetais no controle de insetos já tem ampla aplicação, na maioria das situações com resultados satisfatório, em se tratando do pulgão da erva doce H. foeniculi Abramson et al. (2006) pesquisaram os efeitos dos óleos essenciais de alfazema e citronela em diferentes concentrações e observaram uma eficiência de ambos os produtos, onde a mortalidade dos insetos foi superior a $80 \%$. 
Tabela 1. Mortalidade e mortalidade corrigida usando-se a fórmula de Sun-Shepard do Pulgão $H$. foeniculi $(\mathrm{P}>0,05)$.

\begin{tabular}{lcc}
\hline Tratamentos & Mortalidade (\%) & Mortalidade Corrigida (\%) \\
\hline Óleo + Detergente & $100,0 \mathrm{a}$ & $100,0 \mathrm{a}$ \\
Prev-am & $98,4 \mathrm{a}$ & $86,4 \mathrm{a}$ \\
Provado $^{\circledR} 200 \mathrm{SC}$ & $98,9 \mathrm{a}$ & $81,9 \mathrm{a}$ \\
Água & $87,6 \mathrm{~b}$ & ---- \\
\hline C.V.(\%) & 4,57 & ---- \\
\hline
\end{tabular}

Médias seguidas da mesma letra não diferem estatisticamente pelo teste de Tukey a 5\%.

Após a correção dos dados referentes a mortalidade pelo teste de Sun-Shepard o óleo de linhaça mais detergente continuou com um maior índice de mortalidade de $100 \%$, porém não diferiu estatisticamente dos demais produtos, provavelmente a eficiência desse tratamento tenha sido devido o efeito aditivo do óleo e detergente, uma vez que alguns relatos de pesquisadores indicam o detergente com ação inseticida para pequenos insetos. Segundo Lopes et al. (2009) em trabalhos desenvolvidos com óleo de laranja e o Prevam teve uma eficiência acima de $90 \%$ no controle do $H$. foeniculi. Esses mesmos autores em testes com o pulgão do citros constataram eficiência no uso desses óleos. Os óleos essenciais podem atuar de várias formas nos insetos tanto no comportamento, como atrativos ou repelentes, porém com o contato podem atuar em enzimas digestivas e neurológicas e também interagir com o tegumento do inseto (ISMAN, 2006).

Nesses tratamentos pôde-se observar uma taxa de mortalidade elevada com o uso da água. A ação da água sobre insetos é relatada através da chuva, Farias, (2011) afirma que esse fator abiótico tem um efeito imediato e tardio sobre esses insetos, imediato por causa do efeito mecânico do pingo da chuva e tardio pelo respingo de água e lama que mata por asfixia. Nesse contexto, o que pode ter ocorrido no experimento foi a ação direta da imersão dos insetos na água que recobriu o inseto totalmente, mantandoos por asfixia.

\section{Seletividade a abelha $A$. mellifera}

Quando na exposição dos produtos para A. mellifera, registrou-se que não houve diferença estatística significativa entre os produtos seja para mortalidade corrigida ou 
não, diferindo apenas da testemunha, portanto não foi observada seletividade entre os produtos avaliados (Tabela 2).

Estes produtos provenientes do metabolismo secundário das plantas, são constituídos por misturas complexas de substancias químicas, desempenhando funções importantes nos processos de interações tritróficas (planta-inseto-inimigo natural) e no controle de insetos, ácaros, fungos e nematoides (SCHMUTTERER 1990; OLIVEIRA e VENDRAMIM, 1999, TAVARES e VENDRAMIM, 2005; FAZOLIN et al,.2005). Os produtos botânicos podem ser utilizados na forma de pós, extratos, óleos essenciais e óleos emulsionáveis, e atuam por ingestão, contato e por fumigação (ABRAMSOM et al., 2006).

$\mathrm{O}$ efeito desses produtos nos insetos além da mortalidade, podem incluir, deterrência na alimentação e oviposição, reduções na fecundidade, fertilidade e no processo de crescimento (ROEL et al., 2000; ROEL, 2001; MARTINEZ, 2002; BOEKE et al., 2004).

Tabela 2. Mortalidade e mortalidade corrigida usando a fórmula de Abbott da Abelha Apis mellifera (P> $0,05)$.

\begin{tabular}{ccc}
\hline Tratamentos & Mortalidade (\%) & $\begin{array}{c}\text { Mortalidade Corrigida } \\
(\%)\end{array}$ \\
\hline Óleo+ Detergente & $93,3 \mathrm{a}$ & $36,7 \mathrm{a}$ \\
Prev-am & $100,0 \mathrm{a}$ & $40,0 \mathrm{a}$ \\
Provado $^{\circledR} 200 \mathrm{SC}$ & $100,0 \mathrm{a}$ & $40,0 \mathrm{a}$ \\
Água & $26,6 \mathrm{~b}$ & ---- \\
\hline C.V $(\%)$ & 13,17 & ---- \\
\hline
\end{tabular}

Médias seguidas da mesma letra não diferem estatisticamente pelo teste de Tukey a 5\%.

Em relação ao tratamento com o inseticida Provado, tem como ingrediente ativo o imidacloprido, é considerado altamente tóxico para as abelhas, pois a presença do grupo funcional nitro confere a este inseticida grande afinidade ao receptor nicotínico de acetilcolina e, portanto, alta toxicidade (TOMIZAWA e CASIDA, 2003). Por ser um inseticida sistêmico, o imidacloprido pode também ser encontrado no pólen e no néctar das plantas, assim, o tegumento não é a única rota de exposição das abelhas aos pesticidas, mas também a ingestão de pólen e néctar contaminados (MARICONI, 1983; SCHMUCK et al., 2001; BONMATIN et al., 2003). 


\section{Considerações finais}

O Óleo mais Detergente, o Prev-am e o Provado ${ }^{\circledR} 200$ SC se mostraram eficientes no controle do pulgão da erva-doce $H$. foeniculi, entretanto não são seletivos para a abelha $A$. mellifera.

\section{Referências}

ABBOTT, W. S. A method of computing the effectiveness of an insecticide. Journal of Economic Entomology, Lanham, v. 18, p. 265-267, 1925.

ABRAMSON, C. I.; WANDERLEY, P. A.; MINÁ, A. J. S.; WANDERLEY, M. J. A. Capacity of earwig Marava arachidis (Yersin) to access fennel plants Foeniculum vulgare Mill. in laboratory and field. Ciência Rural, Santa Maria, v. 37, n. 6, p. 15241528, 2007.

ABRAMSON, C. I.; WANDERLEY, P. A.; WANDERLEY, M. J. A.; MINÁ, A. J. S.; SOUZA, O. B. Effect of essential oil from citronella and alfazema on fennel aphids Hyadaphis foeniculi Passerini (Hemiptera: Aphididae) and its predator Cycloneda sanguinea (Coleoptera: Coccinelidae). American Journal of Environmental Sciences, New York, v. 3, n. 1, p. 9-10, 2006.

ABRAMSON, C. I.; WANDERLEY, P. A.; WANDERLEY, M. J. A.; SILVA, J. C. R.; MICHALUK, L. M. The effect of essential oils of sweet fennel and pignut on mortality and learning in africanized honeybees (Apis mellifera L.) (Hymenoptera: Apidae).

Neotropical Entomology, Londrina, v. 36, n. 6, p. 828-835, 2007 b.

ATKINS, E. L.; KELLUM, D.; ATKINS, K. W. Reducing pesticides hazardous to honeybees - Mortality prediction techniques and integrated management strategies. Berkeley: University of California, 1981. 20p.

BARNETT, E. A.; CHARLTON, A. J.; FLETCHER, M. R. Incidents of bee poisoning with pesticides in the United Kingdom, 1994-2003. Pest Management Science, West Sussex, v. 63, n. 11, p. 1051-1057, 2007.

BOEKE, S. J.; BOERSMA, M. G.; ALINK, G. M.; VAN LOON, J. J. A.; VAN HUIS, A.; DICKE, M.; RIETJENS, I. M. C. M. Safety evaluation of neem (Azadirachta indica) derived pesticides. Journal of Ethnopharmacol, Amsterdam, v. 94, n. 1, p. 25 41, 2004.

BONMATIN, J. M.; MOINEAU, I.; CHARVET, R.; FLECHE, C.; COLIN, M. E.; BENGSCH, E. R. A LC/APCI-MS/MS method for analysis of imidacloprid in soils, in plants, and in pollens. Analytical Chemistry, Washington, v. 75, n. 9, p. 2027-2033, 2003.

CARVALHO, R. A. Controle alternativo da cochonilha do carmim na palma forrageira. João Pessoa: Secretaria de Estado de Desenvolvimento Econômico-PB, 2005. 23 p. 
EL-AWADI, M. E.; HASS AN, E. A. Improving growth and productivity of fennel plant exposed to pendimethalin herbicide: stress-recovery treatments. Nature and Science, Michigan, v. 9, n. 2, p. 97-108, 2011.

FARIAS, E. S.; MORAIS, E. G. F.; PICANÇO, M. C.; MOREIRA, S.S.; CAMPOS, S. O.; BACCI, L. Mortalidade de Brevicoryne brassicae por chuva. Horticultura Brasileira, Viçosa, v. 29, n. 2, p. 883-890, 2011.

FAZOLIN, M.; ESTRELA, J. L. V.; CATANI, V.; LIMA, M. S.; ALÉCIO, M. R. Toxidade do óleo de Piper Aduncum L. a adultos de Cerotoma tingomarianus Brechyné (Coleoptera: Chrysomelidae). Neotropical Entomology, Londrina, v. 34, n. 3, p. 485489, 2005.

FERREIRA, R. G.; SOUSA-SILVA C. R. Hyadaphis foeniculi na cultura de erva-doce no Estado de Pernambuco. Pesquisa Agropecuária Brasileira, Brasília, v. 39, n. 12, p. 1265-1266, 2004.

ISMAN, M. B. Botanical insecticides, deterrents, and repellents in modern agriculture and an increasingly regulated world. Annual Review of Entomology, Stanford, v. 51, n. 1, p. 45-66, 2006.

LOPES, E. B. Situação atual do ataque da cochonilha-do-carmim (Dactylopius coccus COSTA): uma nova praga da palma forrageira do cariri paraibano. Relatório TécnicoFitossanitário. EMEPA-PB, 2003. 18 p.

LOPES, E. B.; BRITO, C. H.; ALBUQUERQUE, I. C.; BATISTA, J. L. Potencialidade do óleo de laranja no controle do pulgão preto dos citros. Tecnologia \& Ciência Agropecuária, João Pessoa, v. 3, n. 2, p. 23-26, 2009.

MALASPINA, O.; SILVA-ZACARIN, E. C. M. Cell makers for ecotoxicological studies in target organs of bees. Brazilian Journal of Morphological Sciences, São Paulo, v. 23, n. 3/4, p. 303-309, 2006.

MARICONI, F. A. M. Inseticidas e seu emprego no combate às pragas. 6.ed. São Paulo: Nobel, 1983. 305p.

MARTINEZ, S. S. O nim - Azadirachta indica: natueza, usos múltiplos, produção. Londrina, Instituto Agronômico do Paraná, 2002. 142p.

NEUMANN, P.; CARRECK, N. L.; Honey bee colony losses. Journal of Apicutural Reseacher, London, v. 49, n.1, p. 1-6, 2010.

OLIVEIRA, J. V.; VENDRAMIM, J. D. Repelência de óleos essenciais e pós vegetais sobre adultos de Zabrotes subfasciatos (Boh.) (Coleoptera: Bruchidae) em sementes de feijoeiro. Sociedade Entomológica do Brasil, São Paulo, v. 28, n. 3, p. 549-555, 1999.

PÜNTENER, W. Manual for field trials in plant protection second edition. Agricultural Division, Ciba-Geigy Limited. 1981.

RAMALHO, F. S., FERNANDES, F. S., NASCIMENTO, A. R. B., NASCIMENTO JÚNIOR, J. L., MALAQUIAS, J. B., SILVA, C. A. D. Assessment of fennel aphids (Hemiptera: Aphididae) and their predators in fennel intercropped with cotton with 
colored fibers. Journal of Economic Entomology, Lanham, v. 105, n. 1, 113-119, 2012.

RAMOS, C. L. C.; WANDERLEY JÚNIOR, J. S. A.; ARAÚJO, R. D. S.; WANDERLEY, P. A.; MIRANDA, J. E. Relação entre a infestação de pulgões e o número de joaninhas em plantio de erva-doce orgânico (Foeniculum vulgare) tratado com extrato de melão de São Caetano. In: ENCONTRO DE INICIAÇÃO CIENTÍFICA DA UFPB, 10, 2002. João Pessoa. Anais... João Pessoa: UFPB, 2002, v. 2, p. 38. CDROM.

ROEL, A. R. Utilização de plantas com propriedades inseticidas: uma contribuição para o desenvolvimento rural sustentável. Revista Internacional de Desenvolvimento Local, Campo Grande, v. 1, n. 2, 43-50, 2001.

ROEL, A. R.; VENDRAMIM, J. D.; FRIGHTTO, R.T.S.; FRIGHTTO, N. Efeito do extrato acetato de etila de Trichila pallida Swartz (Meliaceae) no desenvolvimento sobrevivência da lagarta do cartucho. Bragantia, v. 59, n. 1, p. 53-58, 2000.

SCHMUCK, R; SCHONING, R; STORK, A; SCHRAMEL, O. Risk posed to honeybees (Apis mellifera L, Hymenoptera) by an imidacloprid seed dressing of sunflowers. Pest Management Science, West Sussex, v. 57, n. 3, p. 225-238, 2001.

SOUSA-SILVA, C. R.; ILHARCO, F. A. Afídeos do Brasil e suas plantas hospedeiras: lista preliminar. São Carlos: EDUFSCar, 1995. 85p.

STEPHAN, M. C. Toxicidade de produtos fitossanitários utilizados na cultura de citros a operárias de Apis mellifera Linnaeus, 1758. Lavras, 2006. 82p. Dissertação (Mestrado em Agronomia/Entomologia) - Universidade de Lavras.

TAVARES, M. A. G. C.; VENDRAMIM, J. D. Bioatividade da erva-de-Santa-Maria, Chenopoduim ambrosioides L., sobre Sitophilos zeamais Mosts. Neotropical Entomology, Londrina, v. 34, n. 2, p. 319-323, 2005.

TOMIZAWA, M; CASIDA, J. E. Selective toxicity of neonicotinoids attributable to specificity of insect and mammalian nicotinic receptors. Annual Review of Entomology, Stanford, v. 48, n. 1, p. 339-364, 2003. 